\title{
Comorbidity Associations with AATD Among Commercially Insured and Medicare Beneficiaries with COPD in the US
}

This article was published in the following Dove Press journal: International Journal of Chronic Obstructive Pulmonary Disease

\author{
Robert Sandhaus (D) \\ Charlie Strange $\mathbb{D D}^{2}$ \\ Glenda Stone $\mathbb{D i D}^{3}$ \\ M Chris Runken ${ }^{3}$
}

Christopher M Blanchette 4

Reuben Howden ${ }^{5}$

'Division of Pulmonary, Critical Care and Sleep Medicine, National Jewish Health, Denver, CO, USA; ${ }^{2}$ Department of Pulmonary and Critical Care Medicine, Medical University of South Carolina, Charleston, SC, USA; ${ }^{3}$ Global Health Economics \& Outcomes Research, Grifols Shared Services of North America, Inc, Research Triangle Park, NC, USA; ${ }^{4}$ Department of Public Health Sciences, College of Health and Human Services, University of North Carolina at Charlotte, Charlotte, NC, USA; ${ }^{5}$ Department of Kinesiology, College of Health and Human Services, University of North Carolina at Charlotte, Charlotte, NC, USA
Correspondence: Glenda Stone Global Health Economics \& Outcomes Research, Grifols Shared Services of North America, Inc, 79 T.W. Alexander Dr, 4I0I Research Commons, Research Triangle Park, NC 27709, USA Tel + I (919)316-64I5

Email glenda.stone@grifols.com
Introduction: Alpha-1 antitrypsin deficiency (AATD) is often not identified in patients with chronic obstructive pulmonary disease (COPD) until advanced stages of disease, despite the availability of genetic testing. While clinical practice guidelines provide recommendations on patients who should be tested, more refined algorithms are needed to identify COPD patients who are likely candidates for AATD testing and to prevent delays in diagnosis and treatment. The objective of this study was to identify comorbid associations with AATD among patients diagnosed with COPD in the United States.

Methods: Using data from the 2012-2017 PharMetrics Plus Administrative Claims Database and 2011-2014 Medicare Fee for Service 5\% Sample, patients with COPD (ICD-9-CM: 491.xx, 492.xx, or 496, ICD-10-CM J41, J42, J43, J44) and AATD (ICD9-CM: 273.4, ICD-10-CM: E88.01) were identified. Patient demographic and diagnostic characteristics were assessed. Logistic regression models were developed to identify significant predictors of AATD.

Results: A cohort of 344,528 Medicare beneficiaries with COPD (of which $302(0.09 \%)$ also had two diagnoses of AATD) and a cohort of 340,259 commercially insured patients with COPD (of which $1076(0.3 \%)$ also had a diagnosis of AATD) were constructed. Associations with AATD identified in both models included ICD-9-CM and ICD-10-CM codes for chronic pulmonary heart disease, chronic liver disease and cirrhosis, and liver transplant.

Discussion: Significant associations with a diagnosis of AATD among patients with COPD were consistently represented in each of the datasets evaluated, which suggests meaningful comorbidity implications in AATD patients. These findings reinforce the need to test individuals with COPD for AATD as early as possible to help reduce the development of associated comorbid conditions.

Keywords: chronic obstructive pulmonary disease, alpha-1 antitrypsin deficiency, comorbid, genetic

\section{Introduction}

Alpha-1 antitrypsin deficiency (AATD) is a genetic disorder characterized by an increased risk of emphysema or chronic obstructive pulmonary disease (COPD), liver disease, panniculitis, and vasculitis. ${ }^{1-6}$ More than 100 genetic variants of the alpha-1 antitrypsin (AAT) gene have been identified. ${ }^{7,8}$ The predominant phenotype is the normal PI*MM. ${ }^{7,8}$ The mutation most frequently associated with severely reduced levels of AAT and the risk for lung disease is the $\mathrm{Pi}^{*} \mathrm{Z}$ mutation. Approximately $95 \%$ of individuals with AATD are homozygous for the 
$\mathrm{Z}$ variant. ${ }^{7,8}$ Other variants include the $\mathrm{Pi}{ }^{*} \mathrm{~S}$ mutation, which results in mildly reduced serum levels of AAT, and the null mutation, which results in an absence of circulating AAT. ${ }^{9}$

Prevalence of AATD is difficult to ascertain and most often reported for the $\mathrm{Pi}^{*} \mathrm{ZZ}$ genotype. Estimates are based on extrapolation of data from studies in several different populations, including population-based screening, ${ }^{10,11}$ targeted screening in patients with COPD, ${ }^{12,13}$ and genetic epidemiologic surveys. ${ }^{14}$ Based on these data, the prevalence ranges from 1:2500 to 1:5000, indicating that there are an estimated 60,000 to 100,000 individuals in the US with the $\mathrm{Pi}^{*} \mathrm{ZZ}$ genotype. ${ }^{8,15,16}$ However, it is estimated that only a small percentage of patients with a $\mathrm{Pi}^{*} \mathrm{ZZ}$ genotype have been diagnosed. ${ }^{8}$ In addition, individuals who are heterozygous, carrying the $\mathrm{S}$ variant $\left(\mathrm{Pi}^{*} \mathrm{SZ}\right)$, also have AATD and are at risk for emphysema and liver disease. ${ }^{9}$

Environmental exposures, such as smoking and possibly occupational exposure to airway irritants, increase the risk of lung disease in individuals with AATD. Early recognition of AATD offers the opportunity to minimize environmental risk factors and potentially reduce lung damage. $^{17}$

Clinical practice guidelines recommend testing for all patients with symptomatic fixed airflow obstruction, as well as individuals with unexplained bronchiectasis or liver disease. Despite these clinical practice guidelines, ${ }^{15,18}$ the medical literature suggests that AATD is under-recognized and many patients experience a delay in diagnosis. Survey reports indicate that the time from onset of symptoms to the diagnosis of AATD range from 5.6 years to 8.3 years. ${ }^{19-22}$ The delay in diagnosis is thought to be related to healthcare providers' lack of awareness of the disease and methods for testing, and to a lesser extent a perceived lack of efficacy in current therapies. $^{23}$

One of the challenges in diagnosis is that COPD associated with AATD can be difficult to distinguish from nonAATD COPD. Data from the National Heart, Lung, and Blood Institute's AATD Registry study suggest that symptoms, pulmonary function test results, and imaging findings may be similar to the clinical features and findings seen in patients with emphysema or COPD who do not have AATD. ${ }^{24}$ Investigators have sought ways to distinguish AATD associated COPD from non-AATD COPD. In the Long-term Oxygen Treatment Trial, patients with COPD who had severe AATD were more likely to experience a rapid decline in blood oxygen levels with exercise compared to patients with COPD who did not have AATD. The patients with severe AATD were younger (eg, fourth and fifth decade) and had a lower $\mathrm{FEV}_{1} / \mathrm{FVC}$ than patients with non-AATD COPD. ${ }^{25}$ In addition to these characteristics, the disproportionate distribution of emphysematous areas at the base of the lungs is thought to distinguish AATD associated COPD from non-AATD COPD. While changes in the lung bases are more common with AATD, a study by Parr and colleagues found that $36 \%$ of patients with AATD had predominantly apical emphysema on CT imaging, suggesting that an apical distribution should not rule out AATD. ${ }^{26}$ In short, the only way to establish a diagnosis of AATD is via genetic testing.

Early identification of AATD is important for patients to minimize the clinical and psychosocial impact of disease. Patients with severe AATD experience onset of respiratory symptoms at an early age, delays in diagnosis which include visits to multiple healthcare providers before detection of AATD, and negative effects on employment, relationships, and insurance status. ${ }^{19}$ For some patients the severity of organ damage may require lung or liver transplantation. ${ }^{18}$ Another important issue is that family members are at risk of this genetic disease. If younger family members are tested and found to have AATD, then they can be advised to avoid smoking, and environmental and occupational hazards so as to prevent development of lung disease. ${ }^{27}$

Recognizing the impact of AATD on individuals and their families drives the need for earlier recognition of disease and the development of screening algorithms to promote testing for all patients at risk for AATD. The purpose of this study was to identify associations between AATD and diagnostic characteristics among Medicare beneficiaries and commercially insured patients with COPD in the US.

\section{Methods}

Two individual data sets, the 2011-2014 Medicare 5\% Fee for Service sample and the 2012-2017 PharMetrics Plus Administrative Claims Database (commercially insured), were used for this study. Medicare beneficiaries represent $16 \%$ of the total US population or approximately 51 million individuals covered under Part A (hospital) and B (outpatient services). ${ }^{28}$ PharMetrics Plus comprises pooling of fully adjudicated medical and pharmaceutical claims for over 100 million patient lives from more than 
250 health plans across the US. The population in the PharMetrics data set is generally representative of the $<65$ years of age commercially insured US population, with a subset of commercially insured Medicaid and Medicare patients. ${ }^{29}$

Licensing fees were required to obtain access to both the 2011-2014 Medicare 5\% Fee for Service sample and the 2012-2017 PharMetrics Plus Administrative Claims Database. No internal review board (IRB) nor ethics committee review/approval was required for the use of these de-identified health claims data by the administrators of either dataset.

Patients with at least 2 medical claims with a COPD designation (primary or secondary: ICD-9-CM 491.xx Chronic Bronchitis, 492.xx Emphysema, 496 COPD not otherwise specified; ICD-10-CM J41.xx Simple and mucopurulent chronic bronchitis, J42.xx Unspecified chronic bronchitis, J43.xx Emphysema, J44.xx Other chronic obstructive pulmonary disease) during their observation time, and had continuous enrollment during at least a 12-month observation period were included in this analysis. The observation period ranged from 12 months to 66 months. Patients were identified at first COPD diagnosis claim and followed until end of data to determine AATD. AATD patients were required to have at least one additional AATD claim for confirmatory diagnosis (ICD-9-CM: 273.4, ICD-10-CM: E88.01). At least 1 COPD diagnosis had to come before the AATD diagnosis. Those without a second AATD claim were considered non-AATD due to the high likelihood of a rule-out evaluation. Patient demographic and diagnostic characteristics were assessed. The following age categories were used in the model: $0-40$, 41-50. 51-64, 65+ (Medicare cohort only), and age 41-50 was used as the reference group in each.

The primary assessment for this analysis was to identify factors associated with AATD. Potential factors included Elixhauser comorbidities: alcohol abuse, cardiac arrhythmias, blood loss anemia, congestive heart failure (CHF), coagulopathies, deficiency anemia, depression, diabetes (controlled and uncontrolled), drug abuse, fluid and electrolyte disorders, human immunodeficiency virus (HIV)/acquired immune deficiency syndrome (AIDS), arterial hypertension (controlled and uncontrolled), hypothyroidism, liver disease, lymphoma, metastatic cancer, obesity, other neurological disease, paralysis, pulmonary circulation disease, peripheral vascular disease, psychoses, renal failure, rheumatoid arthritis, solid tumors of any kind, valvular disease, peptic ulcer disease (excluding bleeding), and weight loss. ${ }^{30}$ Significant factors associated with AATD (non-protective characteristics) were explored in greater detail.

All statistical analyses were conducted using SAS version 9.3. All tests conducted assumed a two-tailed test of significance and alpha level set a-priori at 0.05 . Demographic and medical characteristics for the cohort were displayed using counts and percentages for categorical variables and measures of central tendency (mean/ median/standard deviation) for continuous variables. Characteristics were presented by total sample and stratified by those with a claim for AATD and those without. Logistic regression models were developed to predict the likelihood of patients having AATD from within the COPD patient population during the observation period. Factors included in the model were grouped age categories, gender, and Elixhauser comorbidities. Odds ratios (OR) are presented as well as 95\% confidence intervals $(\mathrm{CI})$.

\section{Results}

A cohort of patients with COPD was constructed from each of the two datasets, the 2011-2014 Medicare 5\% Fee for Service sample and the 2012-2017 PharMetrics Plus Administrative Claims Database. Within each cohort, the distribution by gender was similar between the AATD and the non-AATD groups. Age cohorts and region (commercially insured population only) were significantly different between the AATD and non-AATD groups $(\mathrm{p}<0.05)$ [see Table 1].

In the Medicare cohort, $4.3 \%$ of non-AATD patients were $41-50$ years of age compared to $12.6 \%$ patients with AATD. In the commercially insured cohort, $17.3 \%$ of nonAATD patients were 41-50 years of age or older compared to $21.9 \%$ of patients with AATD [see Figure 1].

\section{Medicare}

A cohort of 344,528 patients with COPD was constructed, of which $302(0.09 \%)$ also had a diagnosis of AATD. The most common comorbidities among the entire COPD cohort included hypertension-uncomplicated (91\%), cardiac arrhythmia (57\%), and fluid and electrolyte disorders (57\%). Of the patients with COPD and AATD, 45.4\% were male. Most AATD patients were 61-70 years old (37\%), followed by $71+(28 \%), 51-60$ (21\%), 41-50 (13\%), and 31-40 (2\%) years (see Table 2). The AATD cohort had higher rates of pulmonary circulation disorders (29\% vs 23\%; p=0.02) and liver disease (25\% vs $19 \%$; $\mathrm{p}<0.01)$. 
Table I Baseline Characteristics: Medicare and Commercially Insured Cohort

\begin{tabular}{|c|c|c|c|c|c|c|c|c|}
\hline \multirow[t]{3}{*}{ Characteristics } & \multicolumn{4}{|c|}{ Medicare Cohort } & \multicolumn{4}{|c|}{ Commercially Insured Cohort } \\
\hline & \multicolumn{2}{|c|}{ AATD } & \multicolumn{2}{|c|}{ Non-AATD } & \multicolumn{2}{|c|}{ AATD } & \multicolumn{2}{|c|}{ Non-AATD } \\
\hline & (n) & (\%) & (n) & (\%) & (n) & (\%) & (n) & (\%) \\
\hline Total & 302 & $0.1 \%$ & 344,226 & $99.9 \%$ & 1076 & $0.3 \%$ & 339,183 & $99.7 \%$ \\
\hline \multicolumn{9}{|l|}{ Gender } \\
\hline Female & 165 & $54.6 \%$ & 184,897 & $53.7 \%$ & 544 & $50.6 \%$ & 175,798 & $51.8 \%$ \\
\hline Male & 137 & $45.4 \%$ & 159,329 & $46.3 \%$ & 532 & $49.4 \%$ & 163,385 & $48.2 \%$ \\
\hline \multicolumn{9}{|l|}{ Region } \\
\hline Northeast & 38 & $12.6 \%$ & 60,554 & $17.6 \%$ & 205 & $19.1 \%$ & 62,052 & $18.3 \%$ \\
\hline Midwest & 85 & $28.1 \%$ & 85,620 & $24.9 \%$ & 289 & $26.9 \%$ & 89,193 & $26.3 \%$ \\
\hline South & 127 & $42.1 \%$ & 145,323 & $42.2 \%$ & 498 & $46.3 \%$ & 155,209 & $45.8 \%$ \\
\hline West & 52 & $17.2 \%$ & 51,978 & $15.1 \%$ & 84 & $7.8 \%$ & 32,729 & $9.6 \%$ \\
\hline Ex-US & 0 & $0.0 \%$ & 751 & $0.2 \%$ & 0 & $0.0 \%$ & 0 & $0.0 \%$ \\
\hline \multicolumn{9}{|l|}{ Age } \\
\hline $0-10$ & 0 & $0.0 \%$ & 0 & $0.0 \%$ & 0 & $0.00 \%$ & 3,598 & $1.1 \%$ \\
\hline $\mathrm{II}-20$ & 0 & $0.0 \%$ & 29 & $0.0 \%$ & 4 & $0.37 \%$ & 2,289 & $<1.0 \%$ \\
\hline $21-30$ & 0 & $0.0 \%$ & 725 & $0.2 \%$ & 17 & $1.58 \%$ & 4,072 & $1.2 \%$ \\
\hline $31-40$ & 6 & $2.0 \%$ & 3,435 & $1.0 \%$ & 80 & $7.43 \%$ & 13,222 & $3.9 \%$ \\
\hline $4 I-50$ & 38 & $12.6 \%$ & 14,925 & $4.3 \%$ & 236 & $21.9 \%$ & 58,556 & $17.3 \%$ \\
\hline $5 I-64$ & 108 & $35.8 \%$ & 68,091 & $19.8 \%$ & 739 & $68.7 \%$ & 257,446 & $75.9 \%$ \\
\hline $65+$ & 150 & $49.7 \%$ & 257,021 & $74.7 \%$ & 0 & $0.0 \%$ & 0 & $0.0 \%$ \\
\hline
\end{tabular}

\section{PharMetrics Plus}

A cohort of 340,259 patients with COPD was constructed, of which $1076(0.3 \%)$ were diagnosed with AATD. The most common comorbidities among the entire COPD group included hypertension-uncomplicated $(68 \%)$, cardiac arrhythmias (30\%), and depression (35\%). The majority of AATD patients were 51-60 years (49\%), followed by $41-50(22 \%), 61-65(20 \%), 31-40(7 \%), 21-30(2 \%)$, $11-20(<1 \%)$, and $0-10(0 \%)$ years [see Table 3].

When modeling the broader Elixhauser conditions in both cohorts, cardiac arrhythmias, pulmonary circulation disease, and liver disease were found to have significant associations with AATD. The details, including level of significance of the three comorbidities, can be found in Tables 2 and 3. In the PharMetrics Plus cohort, coagulopathy was also found to have a significant association.

Liver transplantation had the strongest association with AATD in both cohorts. In the Medicare cohort, liver abscess and sequelae of chronic liver disease was also found to be associated with AATD. Unique associations in the PharMetrics Plus cohort included symptoms involving cardiovascular systems and varicose veins of other sites.

\section{Discussion}

In this study, claims data from two large databases, Medicare 5\% Fee for Service and PharMetrics Plus, were analyzed to identify co-morbid associations of AATD in patients with COPD. Common associations with AATD identified among the two databases were chronic pulmonary heart disease, chronic liver disease and cirrhosis.

The identification of chronic liver disease and cirrhosis as associated with AATD was an expected finding given that liver disease is a well-documented clinical manifestation of AATD that may occur at any age. ${ }^{2,3}$ A populationbased screening study of 200,000 infants in Sweden reported that $18 \%$ of the infants with $\mathrm{Pi}^{*} \mathrm{Z}$ showed evidence of liver dysfunction over a 6 month follow up period. ${ }^{2}$ Liver disease occurs in adults of all ages with the $\mathrm{Pi}^{*} \mathrm{ZZ}$ genotype, although the risk is higher in adults 50 years of age or older. Evidence of cirrhosis in $12 \%$ of $\mathrm{Pi}^{*} \mathrm{ZZ}$ homozygotes of all ages and in $19 \%$ of patients with the $\mathrm{Pi}^{*} \mathrm{ZZ}$ genotype over the age of 50 years has been reported. ${ }^{1}$ Additional associations with AATD identified were liver transplantation in both datasets and varicose veins of other sites (a code that includes esophageal varices) in the Medicare cohort. These conditions may be 


\section{Medicare Cohort $(\mathrm{n}=344,528)$}

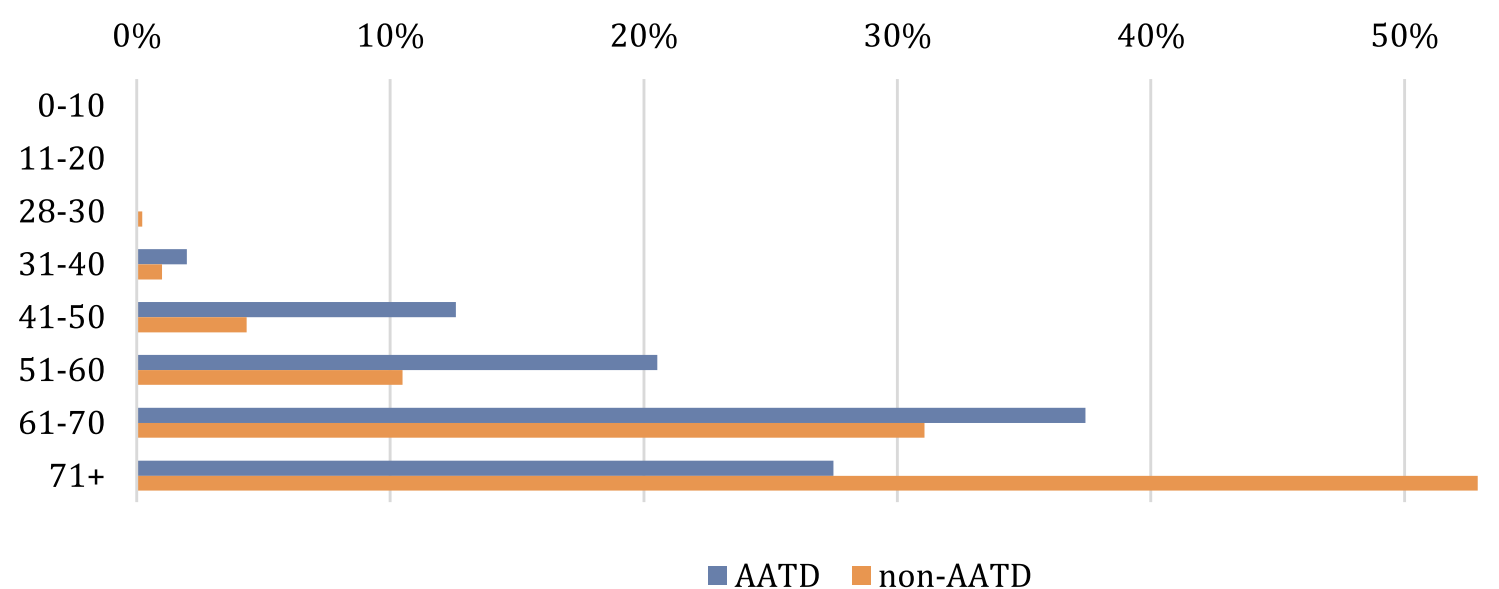

\section{Commercially-Insured Cohort $(\mathrm{n}=340,259)$}

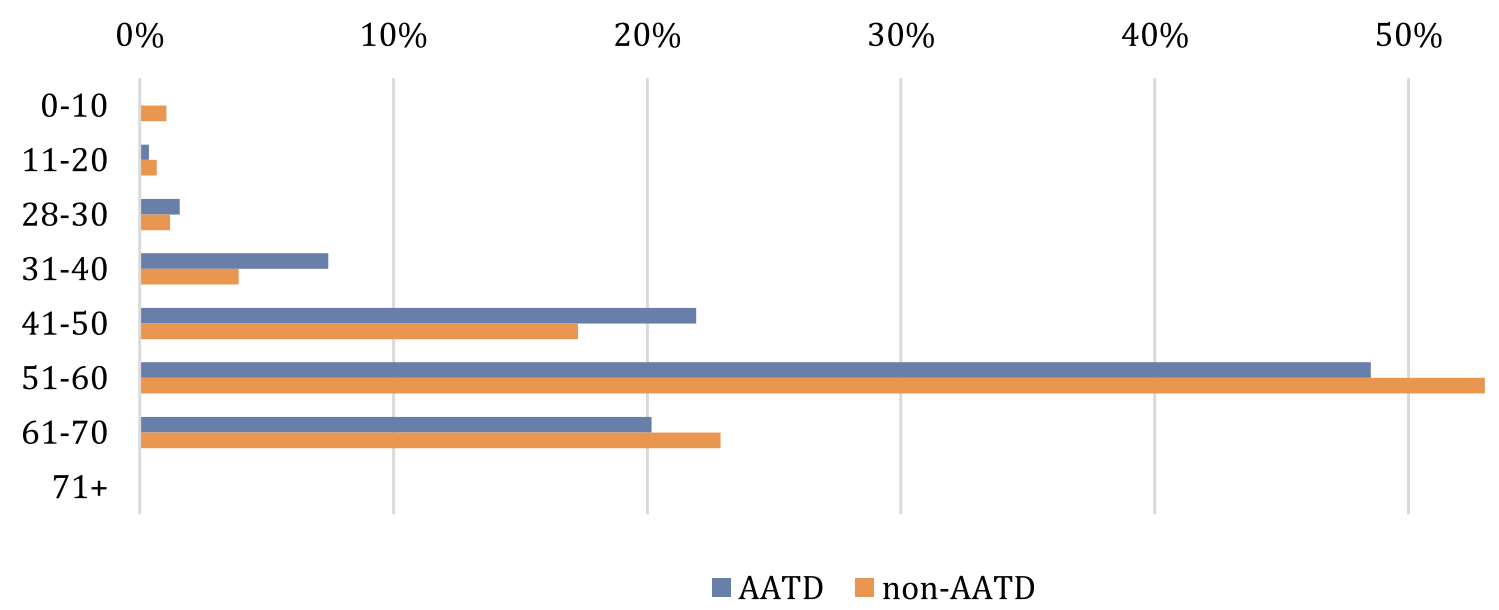

Figure I Age distribution by cohort.

Note: No patients older than 65 were included in the PharMetrics cohort.

related to the presence of liver disease and coded as part of intravenous medication administration.

In the present study, the use of ICD-9-CM and ICD-10$\mathrm{CM}$ codes for chronic pulmonary heart disease was associated with AATD in the Medicare and commercially insured groups, as well as symptoms involving cardiovascular systems (ICD-9_CM-785), in the commercially insured cohort. Other AATD studies have suggested lower or no difference in risk of hypertension in this disease. ${ }^{38-41}$ Another study, by Fahndrich et al, assessing cardiovascular comorbidities in patients with AATD COPD compared to patients with non-AATD COPD found that patients with AATD COPD had a lower frequency of cardiovascular and related diseases (hypertension, chronic heart failure, diabetes, cardiac infarction, and cardiac arterial disease). The investigators suggested that this finding may be related to the pleiotropic effects of the AAT protein, such as the loss of vascular elastic recoil and decreased resistance due to excess activity of elastase, the upregulation and release of angiopoietin-like protein 4 by AAT in complex with fatty acids, or the decreased production of inflammatory cytokines. ${ }^{42}$ It is unclear whether the difference in findings in the present study and the study of Fahndichet al reflects variations in the data collection methodology (patient reported versus claims data) or differences in phenotypes, severity of lung disease, or other geographic or clinical differences between the populations studied. 
Table 2 Associations with AATD: Medicare

\begin{tabular}{|c|c|c|c|c|c|c|c|c|}
\hline \multicolumn{9}{|l|}{ Total Medicare Cohort } \\
\hline \multirow[t]{3}{*}{ Total } & \multicolumn{2}{|c|}{ AATD } & \multicolumn{2}{|c|}{ Non-AATD } & \multirow[t]{3}{*}{ OR } & \multirow[t]{3}{*}{ LCI } & \multirow[t]{3}{*}{ UCI } & \multirow[t]{3}{*}{ p-value } \\
\hline & (n) & (\%) & (n) & (\%) & & & & \\
\hline & 302 & $0.1 \%$ & 344,226 & $99.9 \%$ & & & & \\
\hline \multicolumn{9}{|l|}{ Age Cohorts } \\
\hline $0-40$ & 6 & $2.0 \%$ & 4,189 & $1.2 \%$ & 0.53 & 0.22 & 1.26 & 0.98 \\
\hline $4 I-50$ & 38 & $12.6 \%$ & 14,925 & $4.3 \%$ & \multicolumn{4}{|c|}{ Reference group } \\
\hline $5 I-64$ & 108 & $35.8 \%$ & 68,091 & $19.8 \%$ & 0.62 & 0.43 & 0.90 & 0.22 \\
\hline$\geq 65^{* *}$ & 150 & $49.7 \%$ & 257,021 & $74.7 \%$ & 0.24 & 0.16 & 0.34 & $<0.000$ I \\
\hline Male & 137 & $45.4 \%$ & 159,329 & $46.3 \%$ & 0.97 & 0.77 & 1.22 & 0.78 \\
\hline \multirow{2}{*}{\multicolumn{9}{|c|}{$\begin{array}{l}\text { Comorbidities } \\
\text { Cardiac Arrhythmias }\end{array}$}} \\
\hline & & & & & & & & \\
\hline Conduction Disorders & 10 & $3.3 \%$ & 17,594 & $5.1 \%$ & 0.87 & 0.45 & 1.67 & 0.67 \\
\hline Cardiac Dysrhythmias & 163 & $54.0 \%$ & 190,497 & $55.3 \%$ & 1.04 & 0.81 & 1.34 & 0.74 \\
\hline Symptoms involving Cardiovascular System & 69 & $22.8 \%$ & 58,729 & $17.1 \%$ & 1.24 & 0.94 & 1.65 & 0.13 \\
\hline Mechanical Complication of Cardiac Device, Implant and Graft & 1 & $0.3 \%$ & 6,020 & $1.7 \%$ & 0.28 & 0.04 & 2.15 & 0.22 \\
\hline Cardiac Device in Situ & 19 & $6.3 \%$ & 39,299 & $11.4 \%$ & 0.66 & 0.37 & 1.19 & 0.17 \\
\hline Fitting and Adjustment of Cardiac Device & 8 & $2.6 \%$ & $|8,87|$ & $5.5 \%$ & 0.89 & 0.37 & 2.13 & 0.79 \\
\hline \multicolumn{9}{|l|}{ Pulmonary Circulation Disease } \\
\hline Acute Pulmonary Heart Disease & 31 & $10.3 \%$ & 23,166 & $6.7 \%$ & 1.39 & 0.95 & 2.05 & 0.09 \\
\hline Chronic Pulmonary Heart Disease* & 72 & $23.8 \%$ & 65,165 & $18.9 \%$ & 1.40 & 1.05 & 1.86 & 0.02 \\
\hline Other Diseases of Pulmonary Circulation & 2 & $0.7 \%$ & 1,672 & $0.5 \%$ & 1.06 & 0.26 & 4.31 & 0.94 \\
\hline \multicolumn{9}{|l|}{ Liver Disease } \\
\hline Viral Hepatitis** & 6 & $2.0 \%$ & 8,099 & $2.4 \%$ & 0.28 & 0.12 & 0.67 & 0.00 \\
\hline Varicose Veins of Other Sites & 7 & $2.3 \%$ & 3,643 & $1.1 \%$ & 1.22 & 0.50 & 2.97 & 0.67 \\
\hline Acute and Subacute Necrosis of Liver & 7 & $2.3 \%$ & 3,804 & $1.1 \%$ & 1.28 & 0.58 & 2.82 & 0.53 \\
\hline Chronic Liver Disease and Cirrhosis* & 5 & $1.7 \%$ & 457 & $0.1 \%$ & 1.47 & 1.05 & 2.06 & 0.03 \\
\hline Liver Abscess and Sequelae of Chronic Liver Disease* & 6 & $2.0 \%$ & 8,099 & $2.4 \%$ & 2.01 & 1.10 & 3.68 & 0.02 \\
\hline Other Disorders of Liver & 7 & $2.3 \%$ & 3,643 & $1.1 \%$ & 0.89 & 0.61 & 1.29 & 0.53 \\
\hline Liver Transplant** & 7 & $2.3 \%$ & 3,804 & $1.1 \%$ & 7.01 & 2.67 & 18.40 & $<0.000$ I \\
\hline
\end{tabular}

Notes: ${ }^{*} \mathrm{p}<0.05 ;{ }^{*} \mathrm{p}<0.01$.

Abbreviations: $\mathrm{OR}$, odds ratio; $\mathrm{LCl}$, lower confidence interval; $\mathrm{UCl}$, upper confidence interval.

AATD has been associated with several comorbidities in addition to liver disease and cardiovascular disease, such as vasculitis, rheumatoid arthritis, and inflammatory bowel disease, in case series reports. ${ }^{43-45}$ However, few studies have utilized large claims databases to describe associated comorbidities of AATD in a cohort of patients with COPD in the US. A study by Greulich et al described comorbidities in large samples of patients with COPD, emphysema, and asthma from a German health insurance claims database. ${ }^{46}$ Consistent with the findings of this US-based study, Greulich et al documented a higher prevalence of chronic hepatitis and liver cirrhosis in the patients with AATD compared to the reference population of patients with non-AATD COPD. The prevalence of vasculitis and panniculitis did not differ among the two groups. Ischemic heart disease and depression were more frequent in patients with non-AATD COPD, and osteoporosis was more frequent in patients with AATD. Compared to patients with emphysema, more patients with AATD had arterial hypertension, chronic kidney disease, and diabetes. Compared to patients with asthma, more patients with AATD had arterial hypertension, congestive heart failure, chronic kidney disease, and osteoporosis. ${ }^{46}$ The variations in comorbidities associated with AATD in the current study compared with the study by Greulichet al may reflect geographic and population- 
Table 3 Associations with AATD: PharMetrics Plus

\begin{tabular}{|c|c|c|c|c|c|c|c|c|}
\hline \multicolumn{9}{|l|}{ Total PharMetrics Plus Cohort } \\
\hline \multirow[t]{3}{*}{ Total } & \multicolumn{2}{|c|}{ AATD } & \multicolumn{2}{|c|}{ Non-AATD } & \multirow[t]{3}{*}{ OR } & \multirow[t]{3}{*}{ LCI } & \multirow[t]{3}{*}{ UCl } & \multirow[t]{3}{*}{ p-value } \\
\hline & (n) & (\%) & (n) & (\%) & & & & \\
\hline & 1076 & $0.3 \%$ & 339,183 & $99.7 \%$ & & & & \\
\hline \multicolumn{9}{|l|}{ Age Cohorts } \\
\hline $0-40 *$ & 101 & $9.4 \%$ & 23,181 & $6.8 \%$ & 1.07 & 0.85 & 1.36 & 0.022 \\
\hline $4 I-50$ & 236 & $21.9 \%$ & 58,556 & $17.3 \%$ & \multicolumn{4}{|c|}{ Reference group } \\
\hline $51-64 * *$ & 739 & $68.7 \%$ & 257,446 & $75.9 \%$ & 0.70 & 0.61 & 0.82 & $<0.0001$ \\
\hline Male & 532 & $49.4 \%$ & 163,385 & $48.2 \%$ & 1.09 & 0.96 & 1.23 & 0.1785 \\
\hline \multicolumn{9}{|l|}{ Comorbidities } \\
\hline \multicolumn{9}{|l|}{ Cardiac Arrhythmias } \\
\hline Conduction Disorders & 14 & $1.3 \%$ & 4,323 & $1.3 \%$ & 0.89 & 0.52 & 1.54 & 0.6824 \\
\hline Cardiac Dysrhythmias & 204 & $19.0 \%$ & 58,564 & $17.3 \%$ & 0.93 & 0.79 & 1.10 & 0.3823 \\
\hline Symptoms involving Cardiovascular System** & 217 & $20.2 \%$ & 39,517 & $11.7 \%$ & 1.72 & 1.47 & 2.02 & $<0.0001$ \\
\hline Mechanical Complication of Cardiac Device, Implant and Graft & 1 & $0.1 \%$ & 1,058 & $0.3 \%$ & 0.37 & 0.05 & 2.79 & 0.3325 \\
\hline Cardiac Device in Situ & 17 & $1.6 \%$ & 7,878 & $2.3 \%$ & 0.68 & 0.38 & 1.20 & 0.1805 \\
\hline Fitting and Adjustment of Cardiac Device & 9 & $0.8 \%$ & 4,391 & $1.3 \%$ & 0.77 & 0.35 & 1.67 & 0.5027 \\
\hline \multicolumn{9}{|l|}{ Pulmonary Circulation Disease } \\
\hline Acute Pulmonary Heart Disease & 51 & $4.7 \%$ & 12,397 & $3.7 \%$ & 0.87 & 0.65 & 1.18 & 0.3704 \\
\hline Chronic Pulmonary Heart Disease** & 159 & $14.8 \%$ & $22,94 I$ & $6.8 \%$ & 2.30 & 1.92 & 2.76 & $<0.0001$ \\
\hline Other Diseases of Pulmonary Circulation & 4 & $0.4 \%$ & 818 & $0.2 \%$ & 0.87 & 0.32 & 2.34 & 0.7773 \\
\hline \multicolumn{9}{|l|}{ Liver Disease } \\
\hline Viral Hepatitis* & 21 & $2.0 \%$ & 8,233 & $2.4 \%$ & 0.55 & 0.35 & 0.88 & 0.0115 \\
\hline Varicose Veins of Other Sites $* *$ & 23 & $2.1 \%$ & $2,18 \mid$ & $0.6 \%$ & 2.31 & 1.30 & 4.11 & 0.0042 \\
\hline Acute and Subacute Necrosis of Liver & 2 & $0.2 \%$ & 1,265 & $0.4 \%$ & 0.26 & 0.06 & 1.06 & 0.0611 \\
\hline Chronic Liver Disease and Cirrhosis** & 163 & $15.1 \%$ & 36,482 & $10.8 \%$ & 1.28 & 1.07 & 1.54 & 0.0078 \\
\hline Liver Abscess and Sequelae of Chronic Liver Disease & 31 & $2.9 \%$ & 4,723 & $1.4 \%$ & 0.98 & 0.59 & 1.62 & 0.9248 \\
\hline Other Disorders of Liver & 94 & $8.7 \%$ & 23,846 & $7.0 \%$ & 1.03 & 0.82 & 1.30 & 0.8149 \\
\hline Liver Transplant** & 12 & $1.1 \%$ & 518 & $0.2 \%$ & 4.22 & 2.19 & 8.13 & $<0.0001$ \\
\hline \multicolumn{9}{|l|}{ Coagulopathy } \\
\hline Coagulopathy defects & 52 & $4.8 \%$ & 10,687 & $3.2 \%$ & 1.16 & 0.86 & 1.57 & 0.3353 \\
\hline Purpura and other hemorrhagic events & 68 & $6.3 \%$ & 15,990 & $4.7 \%$ & 0.94 & 0.72 & 1.24 & 0.6635 \\
\hline
\end{tabular}

Notes: ${ }^{*} \mathrm{p}<0.05 ;{ }^{*} \mathrm{p}<0.01$.

Abbreviations: $\mathrm{OR}$, odds ratio; $\mathrm{LCl}$, lower confidence interval; $\mathrm{UCl}$, upper confidence interval.

based differences as well as the heterogenous characteristics of AATD.

In this retrospective analysis, the use of claims databases provided a large cohort of patients with AATD to study. However, this study is limited by the retrospective design, data collection designed for billing/reimbursement rather than research purposes, a reliance on accurate ICD-9-CM/ICD-10-CM coding and is restricted to the data available. There was no information available on genotype (homozygous vs heterozygous), severity of disease, pulmonary function, laboratory testing, patient smoking habits, or treatment with augmentation therapy. The lack of these clinical data should be considered in the interpretation of the findings and may represent other characteristics associated with AATD that this study was not able to identify. Some individuals infusing augmentation therapies may have been seen in the respective health care databases weekly if they were infusing at a center. This would increase the likelihood that additional ICD-9 and ICD-10 codes would be generated. This study looked at factors associated with AATD during an observation period, and 
because AATD is a genetic disease, the temporal association was deemed not to be relevant.

\section{Conclusions}

The findings of this study are consistent with descriptions of clinical manifestations of AATD in the medical literature. Patients present with varying clinical manifestations of AATD across the lifespan. In this study, there were no associations in age, indicating the presence of comorbidities in patients with AATD across all ages and reinforcing the need to test symptomatic patients with COPD or unexplained chronic liver disease, regardless of age, as described in clinical practice guidelines. Limitations of a retrospective study design and use of claims data may have influenced the ability to detect age-dependent associations. These findings reinforce the need to test individuals with COPD for AATD as early as possible to help reduce the impact of associated comorbid conditions.

\section{Acknowledgments}

Dr. Joshua Noone and Ms. Sarah Whitmire provided analytical and writing support for this study.

\section{Disclosure}

Drs. Stone and Runken, are employees of Grifols Shared Services of North America, a subsidiary of Grifols, Inc. Grifols, Inc., a manufacturer of a marketed therapy for the treatment of AATD, funded this study. Drs. Sandhaus, Strange, and Blanchette have each received consultation fees and/or grant support from Grifols, Inc. in the past.

Robert Sandhaus reports Advisory Committee without pay but with reimbursement of travel expenses from Grifols and CSL Behring, outside the submitted work.

Charlie Strange reports grants, personal fees, nonfinancial support from Astra Zeneca, personal fees, nonfinancial support from Glaxo Smith Kline, grants from MatRx, grants, personal fees, non-financial support from CSL Behring, grants, personal fees, non-financial support from Grifols, grants from Takeda, personal fees from Uptake Medical, grants from Nuvaira, grants from CSA Medical, grants, personal fees, non-financial support from Vertex, outside the submitted work.

Glenda Stone reports being an employee of Grifols Shared Services North America, Inc, a manufacturer of a therapy for the treatment of AATD, during the conduct of the study and outside the submitted work.
M Chris Runken reports being an employee of Grifols SSNA, during the conduct of the study and outside the submitted work.

Christopher M Blanchette reports grants from Grifols, during the conduct of the study.

The authors report no other potential conflicts of interest for this work.

\section{References}

1. Larsson C. Natural history and life expectancy in severe $\alpha-1$ antitrypsin deficiency, PiZ. Acta Med Scand. 1978;204:345-351. doi:10.1111/j.0954-6820.1978.tb08452.x

2. Sveger T. Liver disease in $\alpha-1$ antitrypsin deficiency detected by screening of 200,000 infants. N Eng J Med. 1976;294:1316-1321. doi:10.1056/NEJM197606102942404

3. Eriksson S, Carison J, Velez R. Risks for cirrhosis and primary liver cancer in $\alpha-1$ antitrypsin deficiency. $N$ Eng $J$ Med. 1986;314:736-739. doi:10.1056/NEJM198603203141202

4. O'Riordan K, Blei A, Rao MS, et al. $\alpha$-1-antitrypsin deficiencyassociated panniculitis. Transplantation. 1997;53:480-482. doi:10.1097/00007890-199702150-00028

5. Esnault VLM, Testa A, Audrain M, et al. Alpha ${ }_{1}$-antitrypsin genetic polymorphism in ANCA-positive systemic vasculitis. Kidney Int. 1993;43:1329-1332. doi:10.1038/ki.1993.186

6. Elzouki ANY, Segelmark M, Wieslander J, et al. Strong link between

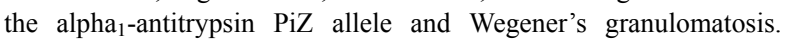
J Intern Med. 1994;236:543-548. doi:10.1111/j.1365-2796.1994. tb00842.x

7. Brantly M, Nukiwa T, Crystal RG. Molecular basis of alpha-1-antitrypsin deficiency. Am J Med. 1988;84(6A):13-31. doi:10.1016/0002-9343(88)90154-4

8. Brantly ML. Efficient and accurate approaches to the laboratory diagnosis of $\alpha 1$-antitrypsin deficiency: the promise of early diagnosis and intervention. Clin Chem. 2006;52:2180-2181. doi:10.1373/ clinchem.2006.078907

9. Crystal RG. $\alpha 1$-antitrypsin deficiency, emphysema, and liver disease: genetic basis and strategies for therapy. $J$ Clin Invest. 1990;85:1343-1352. doi:10.1172/JCI114578

10. O'Brien ML, Buist NR, Murphy WH. Neonatal screening for alpha-1 antitrypsin deficiency. J Pediatr. 1978;92:1006-1010. doi:10.1016/ S0022-3476(78)80388-6

11. Silverman EK, Miletick JP, Pierce JA, et al. Alpha-1-antitrypsin deficiency: high prevalence in the St. Louis area determined by direct population screening. Am Rev Respir Dis. 1989;140(4):961-966. doi:10.1164/ajrccm/140.4.961

12. Lieberman J, Winter B, Sastre A. Alpha-1 antitrypsin Pi-types 965 COPD patients. Chest. 1986;89:370-373. doi:10.1378/chest.89.3.370

13. Rahaghi FF, Sandhaus RA, Brantly ML, et al. The prevalence of alpha-1 antitrypsin deficiency among patients found to have airflow obstruction. COPD. 2012;9(4):352-358. doi:10.3109/15412555. 2012.669433

14. de Serres FJ, Blanco I, Fernandez-Bustillo E. Genetic epidemiology of alpha-1 antitrypsin deficiency in North America and Australia/ New Zealand: Australia, Canada, New Zealand and the United States of America. Clin Genet. 2003;64:382-397. doi:10.1034/ j.1399-0004.2003.00143.x

15. Sandhaus RA, Turino G, Brantly ML, et al. Clinical practice guidelines: the diagnosis and management of alpha- 1 antitrypsin deficiency in the adult. Chronic Obstr Pulm Dis. 2016;3(3):668-682.

16. Stoller JK, Aboussouan LS. Alpha-1 antitrypsin deficiency. Lancet. 2005;365:2225-2236. doi:10.1016/S0140-6736(05)66781-5 
17. Mayer AS, Stoller JK, Bucher Bartelson B, et al. Occupational exposure risks in individuals with $\mathrm{PI}{ }^{*} \mathrm{Z} \alpha_{1}$-antitrypsin deficiency. Am J Respir Crit Care Med. 2000;162:553-588. doi:10.1164/ ajrccm.162.2.9907117

18. American Thoracic Society, European Respiratory Society. American Thoracic Society/European Respiratory Society statement: standards for the diagnosis and management of individuals with alpha-1 antitrypsin deficiency. Am J Respir Crit Care Med. 2003;168 (7):818-900.

19. Stoller JK, Smith P, Yang P, et al. Physical and social impact of alpha-1 antitrypsin deficiency: results of a survey. Cleve Clin J Med. 1994;61:461-467. doi:10.3949/ccjm.61.6.461

20. Campos MA, Wanner A, Zhang G, et al. Trends in the diagnosis of symptomatic patients with alpha-1 antitrypsin deficiency between 1968 and 2003. Chest. 2005;128(3):1179-1186. doi:10.1378/ chest.128.3.1179

21. Stoller JK, Sandhaus RA, Turino G, et al. Delay in diagnosis of a1-antitrypsin deficiency. Chest. 2005;128:1989-1994. doi:10.1378/ chest.128.4.1989

22. Kohnlein T, Janciauskiene S, Welte T. Diagnostic delay and clinical modifiers in alpha-1 antitrypsin deficiency. Ther Adv Respir Dis. 2010;4(5):279. doi:10.1177/1753465810376407

23. Greulich T, Vogelmeier CF. Alpha-1-antitrypsin deficiency: increasing awareness and improving diagnosis. Ther Adv Respir Dis. 2016;10(1):72-84. doi:10.1177/1753465815602162

24. McElvaney NG, Stoller JK, Buist AS, et al. Baseline characteristics of enrollees in the National Heart, Lung and Blood Institute Registry of alpha 1-antitrypsin deficiency. Alpha 1-Antitrypsin Deficiency Registry Study Group. Chest. 1997;111(2):394-403. doi:10.1378/ chest.111.2.394

25. Stoller JK, Aboussouan LS, Kanner RE, et al. Characteristics of alpha-1 antitrypsin-deficient individuals in the long-term oxygen treatment trial and comparison with other subjects with chronic obstructive pulmonary disease. Annals ATS. 2015;12 (12):1796-1804. doi:10.1513/AnnalsATS.201506-389OC

26. Parr DG, Stoel BC, Stolk J, et al. Pattern of emphysema distribution in $\alpha 1$-antitrypsin deficiency influences lung function impairment. $\mathrm{Am}$ $J$ Respir Crit Care Med. 2004;170:1172-1178. doi:10.1164/ rccm.200406-761OC

27. Carpenter MJ, Strange C, Jones Y, et al. Does genetic testing result in behavioral health change? Changes in smoking behavior following testing for alpha-1 antitrypsin deficiency. Ann Behav Med. 2007;33 (1):22-28. doi:10.1207/s15324796abm3301_3

28. FFS Data (2008-2016). Available from: https://www.cms.gov/ Medicare/Health-Plans/MedicareAdvtgSpecRateStats/FFS-Data.html. Accessed January 24, 2019.

29. IQVIA. Available from: https://www.iqvia.com/institute/researchsupport. Accessed January 24, 2019..

30. Elixhauser A, Steiner C, Harris DR, et al. Comorbidity measures for use with administrative data. Med Care. 1998;36:8-27. doi:10.1097/ 00005650-199801000-00004

31. Morgan AD, Zakeri R, Quint JK. Defining the relationship between COPD and CVD: what are the implications for clinical practice? Ther Adv Respir Dis. 2018;12:1-16. doi:10.1177/1753465817750524
32. Divo M, Cote C, de Torres JP, et al. Comorbidities and risk of mortality in patients with chronic obstructive pulmonary disease. Am J Respir Crit Care Med. 2012;186(2):155-161. doi:10.1164/ rccm.201201-0034OC

33. Gershon AS, Mecredy GC, Guan J, et al. Quantifying comorbidity in individuals with COPD: a population study. Eur Respir J. 2015;45:51-59. doi:10.1183/09031936.00061414

34. Chen W, Thomas J, Sadatsafavi M, et al. Risk of cardiovascular comorbidity in patients with chronic obstructive pulmonary disease: a systematic review and meta-analysis. Lancet Respir Med. 2015;3 (8):631-639. doi:10.1016/S2213-2600(15)00241-6

35. Divo MJ, Celli BR, Poblador-Plou B, et al. Chronic obstructive pulmonary disease (COPD) as a disease of early aging: evidence from the EpiChron cohort. PLoS One. 2018;13(2):e0193143. doi:10.1371/journal.pone. 0193143

36. Ahlgren AR, Piitulainen E, Sonessson B, et al. Changes in aortic wall stiffness in men with $\alpha_{1}$-antitrypsin deficiency. Eur $J$ Vasc Endovasc Surg. 1997;14:252-257. doi:10.1016/S1078-5884(97)80236-5

37. Duckers JM, Shale DJ, Stockley RA, et al. Cardiovascular and musculoskeletal co-morbidities in patients with alpha 1 antitrypsin deficiency. Respir Res. 2010;11:173. doi:10.1186/1465-9921-11-173

38. Kumbhare S, Hunt KJ, Nietert PJ, et al. Hypertension prevalence in the US population varies with differences in alpha-1 antitrypsin genotype: a cross sectional study. $B r \quad J$ Med Res. 2015;5 (7):880-888. doi:10.9734/BJMMR/2015/13447

39. Dahl M, Tybjaerg-Hansen A, Nordestgaard BG. Risk of ischemic heart and ischemic cerebrovascular disease in not increased in $\mathrm{S}, \mathrm{Z}$, and 11478A $\alpha_{1}$-antitrypsin carriers of the Copenhagen City Heart Study. Arterioscler Thromb Vasc Biol. 2003;23(11):55. doi:10.1161/ 01.ATV.0000097980.11819.93

40. Boomsma DI, Orbeleke JF, Martin NG, et al. Alpha-1-antitrypsin and blood pressure. Lancet. 1991;337(8756):1547. doi:10.1016/01406736(91)93238-5

41. Huggard PR, West MJ, Summers KM. Alpha 1-antitrypsin deficiency alleles and blood pressure in an Australian population. Clin Exp Pharmacol Physiol. 1996;23(6-7):600-601. doi:10.1111/j.14401681.1996.tb02792.x

42. Fähndrich S, Biertz F, Karch A, et al. Cardiovascular risk in patients with alpha-1-antitrypsin deficiency. Respir Res. 2017;18:171. doi:10.1186/s12931-017-0655-1

43. Lyons PA, Rayner TF, Trivedi S, et al. Genetically distinct subsets within ANCA-associated vasculitis. $N$ Eng $J$ Med. 2012;367 (3):214-223. doi:10.1056/NEJMoa1108735

44. Beckman G, Beckman L, Bielle A, et al. Alpha-1-antitrypsin types and rheumatoid arthritis. Clin Genet. 1984;25(6):496-499. doi:10.1111/j.1399-0004.1984.tb00493.x

45. Yang P, Tremaine WJ, Meyer RI, et al. Alpha1-antitrypsin deficiency and inflammatory bowel diseases. Mayo Clin Proc. 2000;75 (5):450-455. doi:10.1016/S0025-6196(11)64212-2

46. Greulich T, Nell C, Hohmann D, et al. The prevalence of diagnosed $\alpha 1$-antitrypsin deficiency and its comorbidities: results from a large population-based database. Eur Respir J. 2017;49:1600154. doi:10.1183/13993003.00154-2016

\section{Publish your work in this journal}

The International Journal of COPD is an international, peer-reviewed journal of therapeutics and pharmacology focusing on concise rapid reporting of clinical studies and reviews in COPD. Special focus is given to the pathophysiological processes underlying the disease, intervention programs, patient focused education, and self management protocols. This journal is indexed on PubMed Central, MedLine and CAS. The manuscript management system is completely online and includes a very quick and fair peer-review system, which is all easy to use. Visit http://www.dovepress.com/testimonials.php to read real quotes from published authors. 